1. Situação no Brasil;

2. Colaboração STI-INPE;

3. Modelo de avaliação.

Fernando de Mendonça*

* Diretor do Instituto de Pesquisas Espaciais (INPE).

R. Adm. Emp., Rlo de Janeiro,

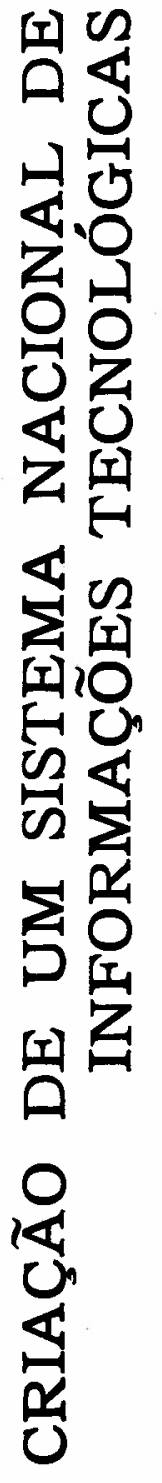

por demais sabido que a informação sempre foi fator decisivo no progresso da ciência e no desenvolvimento tecnológico. Não precisamos aqui também discorrer sobre a revolução das comunicações. Os países industrializados dispõem de sistemas de informações tecnológicas e industriais que resultaram da evolução espontânea de centros e serviços com base numa demanda crescente de informações. Nesses países existem, há muitos anos, sistemas nacionais de informações tecnológica e industrial estruturados e operados através da ação governamental. Esta ação é, reconhecidamente, cada vez mais necessária face ao enorme volume de informações a serem processadas e à grande variedade de demanda. Isto requer a existência de serviços integrados e que utilizem os mais modernos recursos técnicos para a sua operação.

Os governos de países como os Estados Unidos, União Soviética, Inglaterra, França, Japão, Dinamarca, Israel e de alguns países latino-americanos têm promovido a organização do fluxo de informações técnicas às indústrias $\mathrm{e}$ às organizações de pesquisa tecnológica por reconhecerem seu papel essencial na expansão industrial e comercial, bem como sua importância no processo de inovação tecnológica.

Nos Estados Unidos o "sistema" de informações tecnológicas consiste de vários centros independentes e às vezes redundantes que operam sem nenhuma coordenação central. Os centros especializam-se em determinadas áreas técnicas e disseminam informações a usuários em todo o país.

No Japão e em Israel, os centros de informações tecnológicas são órgãos coordenadores com estrutura monolítica, devido principalmente às limitadas áreas geográficas dos respectivos países.

O sistema ITS do Canadá tem duplo objetivo: por um lado coordena os centros que compõem o sistema e por outro estimula a iniciativa de cada centro a atuar independentemente dentro de certos limites.

Organizações governamentais e internacionais como o IDRC do Canadá, UNIDO e OECD incluem em seus programas de assistência técnica estudos sobre sistemas nacionais de informação. Especificamente na América Latina (Ar$14(3): 53-60$, maio/jun. 1974 
gentina, Colômbia e México principalmente), alguns países iniciaram em 1970 estudos visando à implantação de sistemas de informações para a indústria. Também a Unesco e OEA em nível internacional e regional estudam a criação de sistemas de informação.

\section{SITUAÇÃO NO BRASIL}

No Brasil os serviços de informação tecnológica e industrial são precários e muito incompletos. A rapidez do processo de industrialização não permitiu que a infra-estrutura tecnológica e, em particular, os serviços de informação técnica acompanhassem a demanda. No entanto, no estágio de desenvolvimento industrial em que se encontra o País, é indiscutível a necessidade de um sistema de informação tecnológica e industrial que coloque à disposição das empresas (mormente as pequenas e as médias) e instituições nacionais o vasto acervo de informações existentes.

Em 1968 umas poucas iniciativas isoladas como a da Petrobrás, através de sua Divisão de Documentação e Patentes, no campo governamental, e do Centro de Informação sobre Chumbo e Zinco e a do Centro de Informação sobre o Cobre, no campo da iniciativa privada chamaram a atenção para a demanda da informação industrial. Ainda em 1968 foi criado no Instituto Nacional de Tecnologia do Ministério da Indústria e Comércio, o Centro de Informação Tecnológica em convênio com a Confederação Nacional da Indústria.

Essa iniciativa do MIC recebeu inicialmente apoio financeiro do MIC, do CNI e do BNDE, além da assistência técnica da UNIDO e, posteriormente, do IDRC e TIS do Canadá e do British Council.

Em 1969 a sugestão do MIC de criar uma rede nacional de informação tecnológica motivou o Governo federal que em seu documento Metas e Bases para Ação de Governo (1970/72) incluiu o estudo e criação de um Sistema Nacional de Informação Científica e Tecnológica. Foi então instituído pelo Ministério do Planejamento e Coordenação Geral um grupo de trabalho interministerial, coordenado pelo Conselho Nacional de Pesquisas. O resumo do relatório deste grupo de trabalho apresentado ao CNPq em maio de 1973 está transcrito a seguir:
DIRETRIZES BASICAS PARA A IMPLANTAÇAO DO SISTEMA NACIONAL DE INFORMAÇAO CIENTIFICA E TECNOLOGICA (SNICT) *

\section{Objetivo}

O Sistema Nacional de Informação Cientifica e Tecnológica (SNICT) tem como objetivo planejar e coordenar, em âmbito nacional, os trabalhos de informação científica e tecnológica, no sentido do estabelecimento de uma rede nacional de cooperação e intercâmbio, para assegurar o aproveitamento integral dos conhecimentos adquiridos no País e no estrangeiro.

\section{Componentes do SNICT}

São componentes do SNICT o órgão central de coordenação e operação (CNPq), os órgãos de apoio e os subsistemas de informação, sem prejuízo da subordinação ao órgão em cuja estrutura administrativa estiverem integrados.

\subsection{Orgão central de coordenação e operação (CNPq)}

O órgão central do SNICT será o Conselho Nacional de Pesquisas (CNPq), que exercerá as funções de coordenação e operação, através de uma comissão de coordenação.

2.1.1 A comissão de coordenação, presidida pelo presidente do CNPq, será constituída dos coordenadores dos órgãos centrais dos subsistemas de informação e dos órgãos de apoio.

2.1.2 A comissão de coordenação terá a seu serviço uma secretaria Executiva.

2.1.3 Serão as segulntes as atribuições da comissão de coordenação:

a) selecionar objetivos e critérios principais para o desenvolvimento do SNICT;

b) determinar as funçōes do SNICT e de seus componentes;

c) fixar as normas de intercâmbio e comunicação entre as componentes do SNICT;

d) elaborar e/ou aprovar projetos para programação, desenvolvimento e operação do SNICT;

e) proporcionar aos componentes do SNICT recursos humanos e financeiros adicionais de que, eventualmente, necessitem;

f) destinar e supervisionar a aplicação dos recursos provenientes de fundos públicos para ciência e tecnologia, ou de outras fontes que vierem a ser atribuídos por seu intermédio ao SNICT;

g) informar ao Governo Federal os resultados obtidos com o funcionamento do SNICT, com vistas ao desenvolvimento econômico e social do País.

- Documento elaborado pela Comissáo de Redaçáo do Grupo de Trabaho do SNICT (Hagar Espanha Gomes, Presidente do IBBD; Abner L. C. Vicentini, Ministério das Minas e Energia; Angela Lerche Pompeu, Instituto Nacional de Tecnologia; Cégar Teixeira, Ministério da Agricultura; Lydía de Queiroz Sambaquy, Fundaçáo Getullo Vargas) e aprovado na 10." Reunláo Para Implantaçắo do Blstema, em 4 de malo de 1973. 
2.1.4 A secretaria executiva, a ser constituida no CNPq, contará com técnicos especialmente contratados e terá como funções proporcionar à comissão de coordenação o suporte necessário ao desempenho de suas atribuições, expressando em normas executivas a orientação traçada pela comissão de coordenação e acompanhando a efetivação dessas normas.

\subsection{Orgãos de apoío}

Serão órgãos de apolo do SNICT, inicialmente, a B1blioteca Nacional e o Instituto Brasileiro de Biblio. grafia e Documentação (IBBD), este último como centro referencial.

2.2.1 Os órgãos de apoio terão as seguintes funções:

a) oferecer ao SNICT informações e dados de interesse geral;

b) proporcionar coleções de último recurso;

c) proporcionar assessoria e assistêncla técnica;

d) promover o treinamento e o aperfeiçoamento de pessoal para o SNICT.

2.2.2 O centro referencial será operado pelo IBBD, em colaboração com os demais componentes do SNICT, e terá as funçōes de:

a) atuar como centro geral de referêncla sobre blbliotecas, centro de documentação, etc., bem como de informações bibliográficas gerais, de caráter corrente e retrospectivo;

b) compilar e publicar o Catálogo Coletivo Nacional;

c) preparar modelos, programas, códigos, padrōes, etc. necessários à operação do SNICT;

d) consolidar as estatísticas dos subsistemas para avaliação final dos resultados obtidos no SNICT e seu planejamento;

e) orientar os usuários quanto aos subsistemas e fontes que deverão consultar para a obtenção de respostas às suas perguntas.

\subsection{Subsistemas de informação}

Todos os órgãos da administração federal que desenvolvem atividades de documentação e prestam serviços de informação deverão ser agrupados, por áreas de atuação, em subsistemas de informação.

Os subsistemas serão coordenados por centros ou núcleos vinculados aos ministérios ou outros órgãos competentes, que agruparão unidades caracterizadas por áreas de assunto, regiōes, geográficas e funçōes.

São funções dos subsistemas:

a) estudar e avaliar a demanda de informação de seus usuários;

b) desenvolver atividades de documentação e prestar informaçóes em suas áreas de assunto ou missão, de forma normalizada, ráplda, eficiente e precisa; c) coordenar as suas unidades componentes;

d) planejar suas próprias atividades e serviços, bem como solicitar e aplicar recursos financeiros e técnicos necessários às operações;

e) fazer-se representar na coordenação do SNICT pelo coordenador do órgão central ou seu substituto eventual.

\section{Formas de atuação}

\subsection{DO SNICT}

O SNICT atuará de forma descentralizada para a execução dos serviços e atividades da rede de documentação e informação, e de forma centralizada na coordenação dos seus componentes.

\subsection{Dos órgãos de apolo}

Os órgãos de apolo atuarão de forma integrada, dividindo responsabilidades mediante acordos, convênios e outros instrumentos, a critério das normas traçadas pela comissão de coordenação.

\subsection{Dos subsistemas}

Os subsistemas atuarão de forma coordenada, delegando às suas unidades componentes tarefas de informação e documentação.

Quanto às técnicas adotadas, os subsistemas operarão de forma atualizada, fazendo uso, sempre que necessário, dos modernos instrumentos e processos disponíveis para organização automatizada do fluxo de conhecimentos.

\section{Principios básicos}

Os principios básicos nortearão as normas de funcionamento a serem estabelecidas para a implantação do SNICT.

Săo os seguintes os principios básicos:

Compatiblliđade com o Sistema Nacional de Clência e Tecnologia, delineado pelo Decreto n. ${ }^{\circ} 70553$, de 17 de maio de 1972, que define áreas de competência no setor da ciêncla e tecnologia;

Posstbilldade de difusão de informações relevantes e atualizadas;

Rapidez de operação;

Flexibllidade;

Cobertura suficiente do assunto de sua especialidade;

Possibilidade de implantação progressiva dentro dos recursos disponíveis, com utilização imediata em todas as suas fases;

Utillzação de processos e equipamentos modernos de coleta, análise, armazenamento e difusão de informações;

Ligação com outros sistemas de informação, da área científica e tecnológica ou não, nacionais, estrangeiros ou internacionais existentes ou futuros, para a obtenção e fornecimento de dados de interesse mútuo; 
Formação e aperfeiçoamento de pessoal, de todos os níveis, necessário para o seu funcionamento;

Estabelecimento de programas educativos para os seus usuários.

\section{Estrutura do SNICT}

O SNICT terá inicialmente a seguinte estrutura:

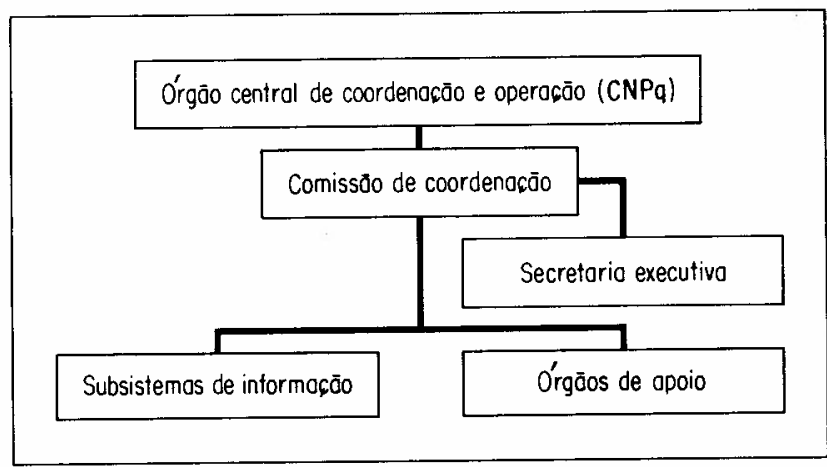

6. Etapas de implantação

A elaboração e o desenvolvimento do projeto e a operação compreenderão as seguintes fases:

6.1 Elaboração e desenvolvimento do projeto de implantação do SNICT.

6.1.1 Análise das condições atuais, estabelecimento da política global, escolha das áreas de atuação prioritárias e estabelecimento das normas de funcionamento.

6.1.2 Desenvolvimento do SNICT: seleção e designação dos centros de informação, definição de suas áreas de atuação; reunião dos centros de informação em subsistemas; estudo de novos centros de informação em potencial.

\subsection{Operação do SNICT}

Em seguida à assinatura do decreto de sua criação, o SNICT iniclará suas operações coordenando as atividades dos subsistemas que gradativamente forem implantados e incorporados ao SNICT, a critério do CNPq.

\section{Sugestóes ao $\mathrm{CNPq}$}

O Grupo de Trabalho do SNICT recomenda ao CNPq: a) elaboração de um projeto de decreto de criação do SNICT;

b) convites aos ministérios para apresentar sugestões sobre sua participação no SNICT através da formação dos seus respectivos subsistemas;

c) convites aos órgãos de apoio para participar do SNICT;

\section{Revista de Administração de Empresas}

d) extinção do grupo de trabalho.

Como resultado deste relatório foì preparada a minuta de decreto que se segue:

\section{Institui o Sistema Nacional de Informação Cientifica e Tecnológica.}

usando das atribuiçōes que lhe confere o artigo 81, itens III e V, da Constituição,

\section{DECRETA:}

Art. 1. ${ }^{\circ}$ Fica instituído, articulado com o Sistema Nacional de Ciência e Tecnologla, previsto no art. $2 .^{\circ}$ do Decreto n. 70553 de 17 de maio de 1972, o Sistema Nacional de Informação Científica e Tecnológica (SNICT), que tem como objetivo planejar, coordenar e difundir, em âmbito nacional, os trabalhos de informação e documentação clentífica e tecnológica, no sentido do estabelecimento de uma rede nacional de cooperação e intercâmblo, para assegurar a pessoas físicas e juridicas de direlto público e privado, o aproveitamento integral dos conhecimentos adquiridos no País e no estrangeiro, de acordo com as diretrizes e prioridades estabelecidas no I Plano Nacional de Desenvolvimento (PND) e aprovadas pela Lei n. 5727 , de 4 de dezembro de 1971.

Art. 2.० Farão parte do SNICT o órgão central de coordenação, os órgãos de apolo e os subsistemas de Informação, sem prejuízo das respectivas subordinações ao órgão em cuja estrutura administrativa estiverem integrados

Art. 3. 0 órgão central de coordenação será o Conselho Nacional de Pesquisas (CNPq), que exercerá as suas funçōes através de uma comissão de coordenação.

§ $1 .^{\circ}$ A comissão de coordenação, presidida pelo presidente do CNPq, e constituída pelos coordenadores dos órgãos centrals dos subsistemas de informação e dos órgãos de apoio, terá as seguintes atribuições:

a) selecionar objetivos e critérios principais para o desenvolvimento do SNICT;

b) determinar as funções do SNICT e de seus componentes;

c) fixar as normas de intercâmbio e comunicação entre os componentes do SNICT;

d) elaborar e/ou aprovar projetos para programação, desenvolvimento e operação do SNICT;

e) pleitear, junto aos órgãos governamentais, os recursos humanos e financeiros de que eventualmente necessitem os componentes do SNICT;

f) destinar e coordenar a aplicação dos recursos provenientes de fundos públicos para ciência e tecnologia, ou de outras fontes que vierem a ser atribuídos, por seu intermédio, ao SNICT. 
§ 2.0 A comissão de coordenação terá a seu serviço uma Secretaria Executiva.

Art. 4. ${ }^{\circ}$ Serão órgãos de apolo do SNICT, iniclalmente, a Biblioteca Nacional e o Instituto Brasileiro de Bibliografia e Documentação (IBBD), este último como centro referencial.

Parágrafo único. Os órgãos de apoio terão as seguintes atribulções:

a) prestar informações e serviços que forem sollcitados pelo SNICT;

b) proporcionar assessoria e assistêncla técnica ao SNICT;

c) promover o treinamento e o aperfeiçoamento de pessoal para o SNICT;

d) fazer-se representar na comissão de coordenação.

Art. 5. Serão agrupados em subsistemas de informação, de acordo com as respectivas áreas de atuação, os órgãos da Administração Federal que desenvolvem atividades de documentação e informação em clência e tecnologia.

$\S 1.0$ Os subsistemas de informação serão coordenados por centros ou núcleos vinculados aos ministérios ou outros órgãos componentes.

§ 2. O SNICT compreenderá, Inicialmente, os seguintes subsistemas:
a) informação clentifica;
b) informação tecnológica e industrial;
c) informação sobre serviços de Infra-estrutura;
d) informação agrícola;
e) coleta de informação no exterior;
f) informação sobre saúde;
g) Informação sobre educação;
h) informação sobre minas e energia.

Art. 6. Os subsistemas de Informação, cujos componentes serão órgãos públicos ou privados, terão as seguintes atribuições:

a) estudar e avaliar a demanda de informação de seus usuários;

b) desenvolver atividades de documentação e difundir informaçōes em suas áreas de assunto ou missão, de forma normalizada;

c) coordenar as suas unidades componentes; d) planejar suas próprias atividades e serviços, bem como solicitar e aplicar recursos financeiros e técnlcos necessários às operações;

e) fazer-se representar na comissão de coordenação.

Art. 7.0 A organização, funcionamento e implanta ção do SNICT serão disciplinados em regimento proposto pela Comissão de Coordenação e aprovado pelo presidente do CNPq.

Art. 8. 0 presente Decreto entrará em vigor na data de sua publicação.

Brasília,

Decreto baseado nesta minuta deverá ser assinado por Sua Excelência, o Presidente da República, neste semestre, instituindo o Sistema Nacional de Informações Científicas e Tecnológicas (SNICT).

Um dos principais subsistemas do SNICT será o Subsistema de Informação Tecnológica e Industrial (SSITI) no Ministério da Indústria e Comércio (INT-CIT).

Este subsistema (SSITI) terá por objetivos: assegurar às empresas e aos institutos tecnológicos uma rede de serviços de informação, capacitada a manter no País um fluxo organizado de informações técnicas necessárias ao desenvolvimento da capacidade de inovação nacional;

integrar o Subsistema de Informação Tecnológica e Industrial (SSITI) ao Sistema Nacional de Informação Científica e Tecnológica (SNICT);

agrupar centros de informação tecnológica e industrial já existentes ou os que vierem a ser criados, sob uma coordenação única a fim de evitar duplicações desnecessárias, somando todos os esforços em benefício da economia de custos e da padronização dos serviços de informação do País, coerente com o que prescreve o Plano Básico de Desenvolvimento Científico e Tecnológico (PBDCT-1973/74).

Internamente, no Ministério da Indústria e Comércio (MIC), o SSITI deverá interagir com o Instituto Nacional de Propriedade Industrial (INPI), o Instituto Nacional de Pesos e Medidas (INPM) e o Instituto Nacional de Tecnologia (INT). Este instituto em fase de reestruturação passará a denominar-se Instituto Nacional de Tecnologia Industrial (INTI). To- 
dos estes institutos são parte integrante da Secretaria de Tecnologia Industrial (STI) do MIC.

O Centro de Informação Tecnológica (CIT) do INT, como mencionado anteriormente, vem desenvolvendo trabalhos no sentido da estruturação do SSITI, sob a liderança da Dr.a Ângela Pompeu.

As várias fases do fluxo de trabalho são apresentadas na figura 1.

Figura 1 - Subsistema de informaçāo tecnológica e industrial. Fluxo de trabalho

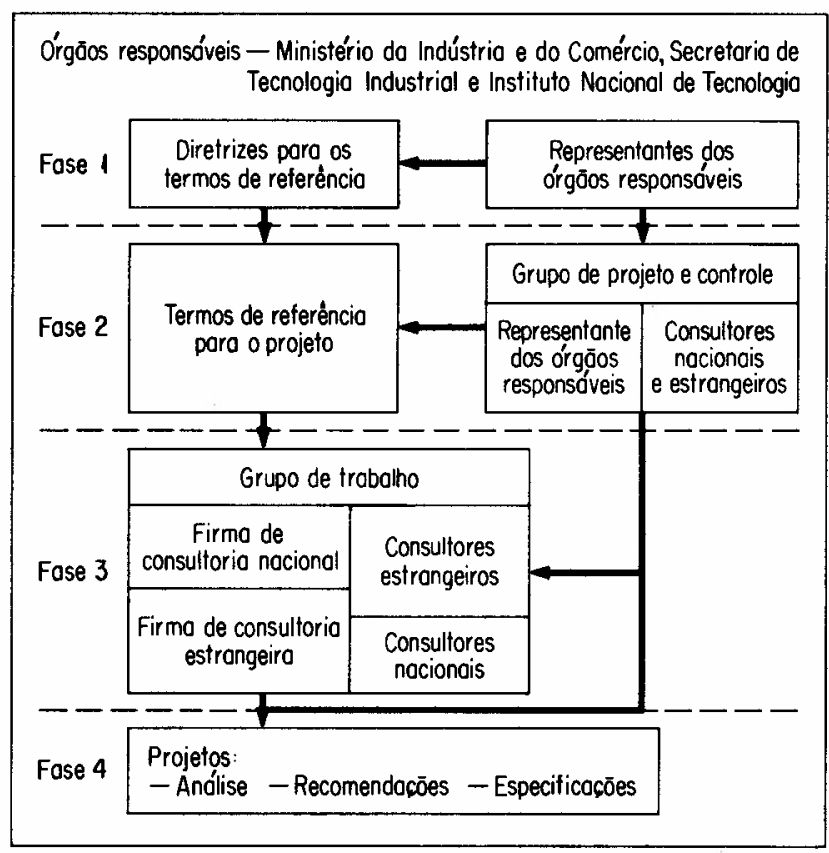

2. COLABORAÇÃO STI-INPE

Tendo em vista a existência de um grupo no Instituto de Pesquisas Espaciais (INPE) com formação em engenharia de sistemas, foi proposto um projeto ou plano-piloto de colaboração com a Secretaria de Tecnologia Industrial (STI) e seus institutos. Espera-se para futuro muito próximo a assinatura de convênio entre essas instituições. As três características principais a serem atendidas pelo projeto são: capacidade de investigação, capacidade de desenvolvimento e capacidade de operação.

Essas características deverão possibilitar, entre outras coisas, o conhecimento das necessidades de informação e assistência aos industriais brasileiros, o conhecimento das fontes de informações interna e externa do Brasil, definição de critérios de interface com tais fontes, uniformização do modo de operação dos centros no Brasil, determinação dos equipamentos adequados ao processamento e disseminação de informações, capacitação e aperfeiçoamento de profissionais, estabelecimento do flu- xo de interação do SSITI nas suas diversas partes, determinação do custo de investimento e operação.

Um importante aspecto deste projeto é estabelecer critérios para aprovação de projetos de centros de informação que estão proliferando em diversas instituições de tecnologia.

O projeto também fornecerá os elementos para que se possam estabelecer os termos de referência para implantação do SSITI em condições realistas, levando-se em conta inovações tecnológicas num horizonte que inclua pelo menos a presente década.

E apresentado a seguir o Diagrama de Fluxo de Trabalho para estruturação do SSITI, que passamos a descrever:

0.0 Os estudos preliminares já foram realizados pelo Centro de Informação Tecnológica do INT e conduziram à elaboração deste planopiloto.

1.0 Pelo convênio que se estabelecerá entre INPE e STI, que deverão constituir uma equipe coordenadora que irá encarregar-se dos aspectos legais e também de garantir a obtenção dos recursos financeiros, além de se responsabilizar pela coordenação das atividades que se seguem.

2.0 A seguiir deverão ser contatadas várias firmas de consultoria que trabalham no campo da informação, tanto no Brasil como no exterior. O trabalho preliminar elaborado pelo CIT constituiu-se inclusive de um rápido levantamento dessas firmas. Assim sendo a escolha da(s) firma (s) de consultoria que deverá(ão) auxiliar no planejamento das atividades a serem desenvolvidas não deverá ser muito demorada.

3.0 Escolhidos os consultores deverão ser feitos os contratos necessários e então uma equipe de planejamento ficará constituída.

4.0 Essa equipe de planejamento inicialmente irá reavaliar os estudos preliminares e identificar macroatividades de forma a poder estabelecer uma estrutura organizacional para o projeto-piloto. Esta estrutura, dentro das possibilidades, deverá ser suficientemente flexível 


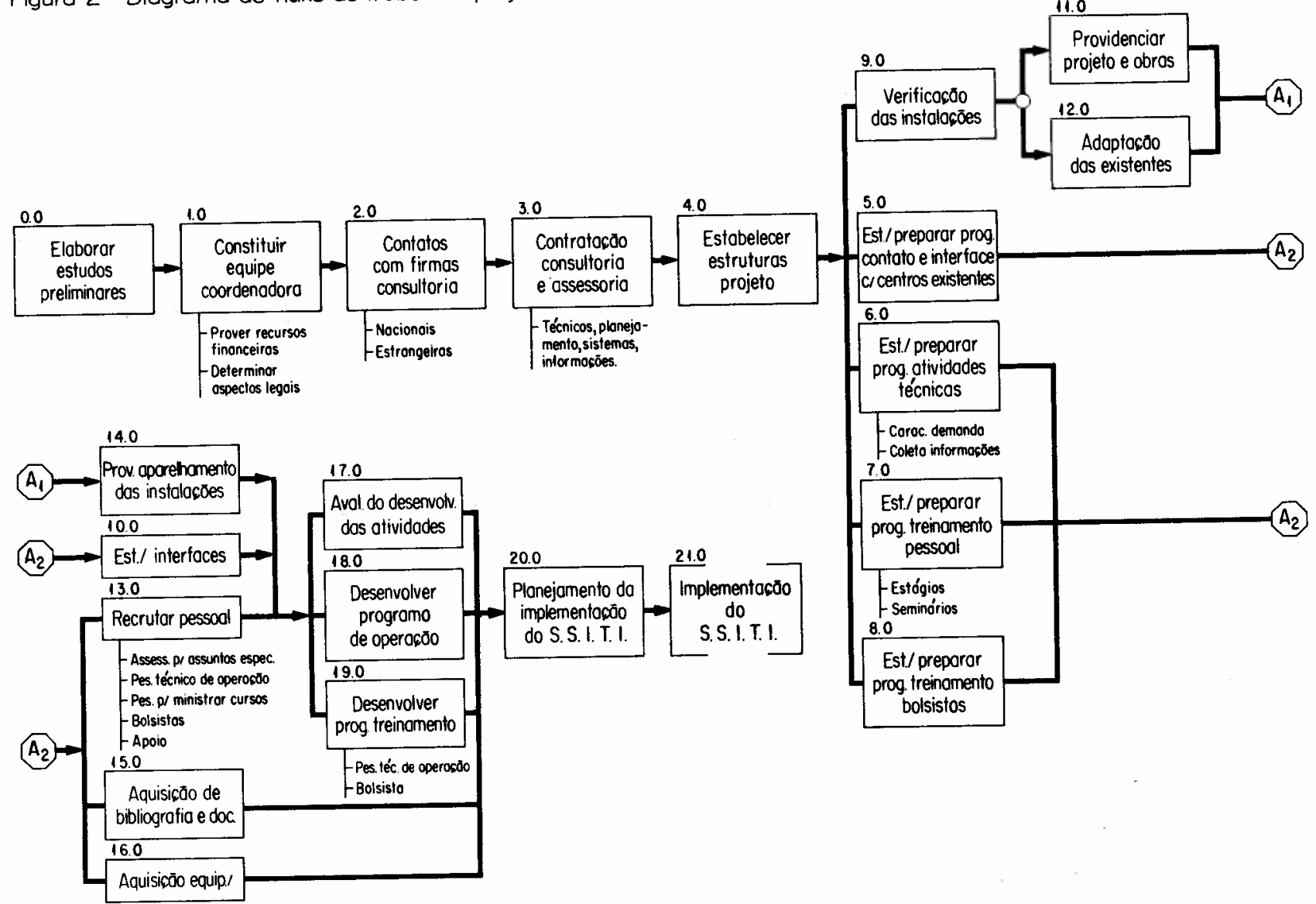

para permitir ajustes necessários, evidenciados pela operação do plano-piloto, de tal maneira que uma estrutura mais estável e eficiente possa ser utilizada na implementação do SSITI. A partir deste ponto várias atividades serão desenvolvidas simultaneamente.

5.0 Deverá ser elaborado um programa estabelecendo critérios para o levantamento e contatação com os centros de informação já existentes. Deverão ser fixados os objetivos específicos que se pretende atingir com o estabelecimento dessas interfaces bem como a metodologia para a execução das mesmas. Assim, toda a problemática de uniformização das atividades serão aqui abordadas, além de outros interesses como treinamento de pessoal, utilização das informações, etc.

6.0 O programa das atividades técnicas, tais como: caracterização de demanda, coleta de informações, classificação e catalogação, sistema de codificação, processamento da informação, disseminação, entre outras, será baseado na experiência adquirida pelo CIT com assis- tência de consultores. Este programa envolve a definição detalhada das tarefas que serão executadas dentro das macroatividades identificadas pela equipe de planejamento. Naturalmente toda a parte referente à normalização e padronização de tratamento e processamento da informação será aqui considerada.

7.0 Dado que experiências desta envergadura têm sido pouco desenvolvidas no Brasil, prevêse um intensivo programa de treinamento de pessoal. necessário um conhecimento e compatibilização dos vários enfoques utilizados neste tipo de trabalho. Assim torna-se necessário o desenvolvimento de um programa de treinamento, envolvendo provavelmente estágios em firmas similares, tanto no Brasil como no exterior, e também seminários envolvendo os outros centros de informações existentes.

8.0 Preocupados com a implementação do CIT, e devido à falta de recursos humanos existentes no mercado nacional, o projeto-piloto terá também a finalidade de preparar pessoal na área. Assim o programa de bolsistas constará de cursos, seminários e trabalhos práticos 
que possibilitarão a utilização imediata do pessoal na fase de implementação.

$9.0,11.0,12.0,14.0$ A medida que forem determinadas as atividades que serão executadas e a quantidade de pessoal necessário ao projeto, deverá existir a preocupação com as instalações físicas adequadas ao trabalho. Neste ponto poderão ser consideradas a utilização de instalações existentes ou até mesmo possíveis construções. Concomitantemente, deverá ser providenciado o aparelhamento das instalações.

10.0 Os contatos com os outros bancos de dados existentes serão efetuados, gradativamente, através de seminários e estágios, tanto do pessoal do centro como do pessoal da indústria no centro, de maneira a facilitar a consecução dos objetivos propostos.

13.0 Desde que já se tenha definido o local de atuação do centro, e programado suas atividades, poderá ser efetuado o recrutamento do pessoal necessário para assessoria em assuntos específicos, do pessoal técnico de operação, do pessoal para ministrar os cursos e seminários e daqueles que serão preparados para atuar na expansão do centro.

15.0 A documentação que será utilizada pelo pessoal será adquirida de acordo com sua necessidade. Existe uma bibliografia básica; entretanto grande parte dos assuntos serão determinados a partir do início da experiência.

16.0 A medida que forem dimensionadas as instalações e definida a quantidade de pessoal do centro, deverá processar-se a aquisição dos equipamentos e material permanente necessário à execução do plano.

17.0 Durante a execução das atividades programadas, com as informações coletadas processar-se-á a avaliação da operação. Esta avaliação deverá preocupar-se com os procedimentos de execução, com a programação feita, e ao mesmo tempo adaptar essas programações à Revista de Administração de Empresas realidade do experimento, de modo que ao final do período, seja possível a elaboração de planos de continuidade do processo.

18.0, 19.0 O desenvolvimento dos programas propostos será de forma gradativa e envolvente, de maneira que seja possível uma adequação dos mesmos à proporção em que sejam acumuladas novas experiências no plano-piloto.

\section{MODELO DE AVALIAÇĀO}

Modelos de avaliação de um projeto levam em conta aspectos normativos e somativos.

$O$ aspecto normativo consiste em dividir o projeto em fases distintamente identificáveis, onde cada fase deve assegurar que a sua execução traga benefícios imediatos que justifiquem o fornecimento de recursos; ao fim de cada fase, deve haver uma tomada de decisão a respeito da execução da próxima. Neste sentido, de acordo com o cronograma do projeto, é natural que tenhamos, após o término da fase de planejamento, uma avaliação de dois em dois meses.

$O$ aspecto somativo corresponde à avaliação da aplicação de recursos num contexto mais amplo, onde as atividades e possíveis conseqüências do projeto sejam relacionadas com o desenvolvimento de outros setores. interessante que um grupo coordenador de um projeto como do SSITI esteja consciente destes conceitos e disponha de um modelo para aplicá-los.

Finalizando este trabalho, espero ter dado uma visão global, embora muito superficial, da situação do setor de informação tecnológica no Brasil. Seria muito mais interessante estar apresentando resultados, mesmo com erros, do que planos. Mesmo assim, é preferível falar em planos, que têm altas probabilidades de serem implantados, do que na ausência de planos. Creio firmemente que, durante os próximos dois anos, o Brasil terá dedicado mais recursos e atenção à informação tecnológica do que nos últimos 10 anos, pelo menos. 